\title{
Anatomia descritiva aplicada à cinesiologia e biomecânica básica dos músculos da cintura peitoral, estilopódio e zeugopódio do jacaré do papo amarelo
}

\author{
Descriptive anatomy applied to the kinesiology and basic biomechanics of the pectoral girdle, \\ stylopodium and zeugopodium muscles of broad snouted caiman
}

\section{Mariluce Ferreira Romão ${ }^{\mathrm{I}}$ André Luiz Quagliatto Santos ${ }^{\mathrm{I}}$ Fabiano Campos Lima ${ }^{\mathrm{II}}$}

RESUMO

\begin{abstract}
Objetivou-se identificar os parâmetros de origem $e$ inserção musculares da cintura peitoral e membro torácico de Caiman latirostris, mediante abordagem anatômica, cinesiológica e biomecânica básica. Foram utilizados dois exemplares de C. latirostris, machos, medindo, em média, $1,50 \mathrm{~cm}$ de comprimento, adultos, pertencentes ao acervo do Laboratório de Ensino e Pesquisa em Animais Silvestres, Universidade Federal de Uberlândia/MG, Brasil. Foi notada postura isométrica entremeando movimentos rotativos, além de grande área de secção transversa, na maioria dos músculos extensores e estabilizadores, conferindo-lhes, maior força, denotando inferências funcionais e organizacionais. Foi possível reconhecer e predefinir o comportamento da espécie investigada, relacionando duração, direção e dimensão dos níveis de ação.
\end{abstract}

Palavras-chave: anatomia, Caiman latirostris, répteis.

\section{ABSTRACT}

The parameters of muscle origin and insertion points in the pectoral girdle and forelimbs of Caiman latirostris were identified by basic anatomical, kinesiological and biomechanical approach. This identification was made with two adults males specimens of $\boldsymbol{C}$. latirostris, on average, $1.50 \mathrm{~cm}$ in length, belonging to the collection of the Wild Animal Research Laboratory of the Federal University of Uberlândia/MG, Brazil. In this study, isometric postures intercalated with rotary movements were found, as well as a large cross-sectional area in most of the extensor and stabilizer muscles, giving them greater strength and denoting functional and organizational inferences.
Based on the findings, it was possible to recognize and predefine the behavior of the species under investigation, correlating the duration, direction and dimension of the activity levels.

Key words: anatomy, Caiman latirostris, reptiles.

\section{INTRODUÇÃO}

Diversas posturas podem ser adotadas pelos tetrápodes na locomoção. Em algumas, os membros são mantidos ao lado do corpo, ocasionando movimentos intersegmentados, como salamandras e alguns lagartos (CABELGUEN, et al., 2003), em outras, abaixo, em relação ao corpo, como os mamíferos e aves (REILLY, 2000), e, ainda, crocodilianos e iguanas conseguem assumir diferentes posturas, apesar de apresentarem duração restrita nas ações. Vale ressaltar que pode haver variações intraespecíficas e, portanto, posturas intermediárias (eretas, semi-eretas e rastejantes) (BLOB \& BIEWENER, 2001; REILLY \& BLOB, 2003).

O jacaré do papo amarelo, Caiman latirostris, é um crocodiliano da América do Sul, de porte médio, considerado em risco de extinção até 2003 e, atualmente, classificado pela lista vermelha da IUCN, em baixo risco, com uma população

'Laboratório de Ensino e Pesquisa em Animais Silvestres, Faculdade de Medicina Veterinária, Universidade Federal de Uberlândia (UFU), Rua Piauí, Bloco 4s, Bairro Jardim Umuarama, 38400-902, Uberlândia, MG, Brasil. E-mail: mariluce.ferreira@ terra.com.br. *Autor para correspondência.

"Laboratório de Anatomia Humana e Comparativa, Universidade Federal de Goiás (UFG), Unidade Jatobá, Goiânia, GO, Brasil. 
selvagem em torno de 250.000 a 500.000 (BRITTON, 2009; QUEIROZ \& AOYAMA, 2009). Encontrados em manguezais, ilhas e pântanos (FUSCO-COSTA et al., 2008), distribuem-se geograficamente desde o nordeste do Brasil ao extremo sudeste da Bolívia, incluindo não só o norte da Argentina, Uruguai, Paraguai, como também as bacias hidrográficas dos rios Paraná e São Francisco, extensivos a pequenas bacias costeiras do leste do Brasil (BRAZAITIS et al., 1990).

Estudos acerca dos membros torácicos dos crocodilianos são escassos (DODSON, 2003; LAITMAN, 2003), em detrimento ao foco nos membros pelvinos, tendo em vista a sua importância no aporte locomotor terrestre e na propulsão aquática (FARMER \& CARRIER, 2000; BLOB \& BIEWENER, 2001; REILLY \& BLOB, 2003). Há relatos sobre a descrição do ombro e braço do Crocodillus Acutus (FÜRBRINGER,1876 apud LAITMAN, 2003); e do antebraço de Alligator mississippiensis, Caiman crocodilus e Crocodylus acutus (RUDINGER, 1868 apud LAITMAN, 2003), não encontrados os documentados originais, afim de serem referenciados, diretamente, nesta compilação.

Abordagens anatômicas podem ser relevantes, fornecendo informações morfológicas e biológicas de determinada espécie. A descrição da anatomia muscular (origem e inserção) da cintura peitoral, estilopódio e zeugopódio de $\boldsymbol{C}$. Latirostris pode contribuir para o conhecimento de aspectos anatômicos, cinesiológicos e biomecânicos básicos, concernentes a essa espécie. Aspectos do comportamento locomotor desses animais parecem fornecer subsídios para o auxílio em projetos de manejo economicamente viáveis, bem como na medicina terapêutica desses animais, complementados com os dados que constam nesta compilação.

\section{MATERIAL E MÉTODOS}

Foram utilizados dois exemplares de Caiman latirostris, machos, medindo, em média, 1,50 $\mathrm{cm}$ de comprimento, adultos, pertencentes ao acervo do Laboratório de Ensino e Pesquisa em Animais Silvestres, Universidade Federal de Uberlândia, MG, Brasil, fixados em solução de formol a $10 \%$.

Foram viabilizados os procedimentos de dissecação, iniciados com uma incisão longitudinal ao longo da linha mediana ventral do tronco, rebatendo- se a pele lateralmente, da região cervical até o nível caudal torácico. A cintura peitoral, estilopódio e zeugopódio foram mantidos fixados em solução de formol a $10 \%$ e fotografados com câmera digital.

$\mathrm{Na}$ sequência, foi realizada a individualização muscular da cintura peitoral, estilopódio e zeugopódio, seguida da identificação dos músculos e, por conseguinte, retirada dos membros, para melhor observação das origens e inserções musculares.

Utilizou-se forma comparativa com as cinco espécies estudadas por MEERS (2003), referenciando quatro Alligator missipiensis, um Crocodillus siamensis, dois Crocodillus acutus, dois Osteolaemos tetraspis, um Gavialis gangeticus, acrescido de análises locomotoras. Os termos direcionais utilizados foram embasados na NOMINA ANATÔMICA VETERINÁRIA (2005), bem como os músculos, em informações inferidas por MEERS (2003).

\section{RESULTADOS}

Os resultados seguem descritos nas tabelas $1,2,3$ e 4 , referenciando as descrições das origens e inserções dos músculos, que atuam nos movimentos da cintura peitoral, estilopódio e zeugopódio do Caiman latirostris, relacionando à musculatura axial envolvida nas ações, em conformidade com as figuras 1 e 2 .

\section{DISCUSSÃO}

No presente estudo, foi notada postura isométrica entremeando movimentos rotativos, além de grande área de secção transversa, na maioria dos músculos extensores e estabilizadores, conferindo-lhes, maior força, denotando inferências funcionais e organizacionais, conforme a afirmação de HILDEBRAND \& GOSLOW (2006), discorrendo que "[...] a força máxima que um músculo pode exercer é igual à força de contração de uma de suas fibras, multiplicada pelo número total de fibras [...]'(p.176). O membro torácico dos crocodilianos apresenta considerável predominância de musculatura, ativamente, extensora, tanto para a articulação do ombro, como para o antebraço, permanecendo em extensão a maior parte do tempo. Nos quadrúpedes, vários músculos que encurtam em ação flexora para mover a articulação na fase de elevação postural agem em contração isométrica ou excêntrica nos 
Anatomia descritiva aplicada à cinesiologia e biomecânica básica dos músculos da cintura peitoral, estilopódio e zeugopódio do jacaré.633

Tabela 1 - Origem, inserção e ação dos músculos dorsais superficiais, dorsais profundos da cintura peitoral de Caiman latirostris.

\begin{tabular}{|c|c|c|c|}
\hline Músculo & Origem & Inserção & Ação \\
\hline Trapézio & $\begin{array}{l}\text { Fáscia tóraco dorsal cranial } \\
\text { ao úmero (nivel cervical e } \\
\text { torácico). }\end{array}$ & Ao longo da margem cranial da escápula. & $\begin{array}{l}\text { Protração cranial da } \\
\text { escápula. }\end{array}$ \\
\hline Latíssimo do dorso & $\begin{array}{l}\text { Fáscia tóraco dorsal } \\
\text { (contínuo com o trapézio). }\end{array}$ & $\begin{array}{l}\text { Distal à superfície articular proximal do úmero, } \\
\text { cranial ao tríceps curto intermédio (tendão } \\
\text { sobreposto ao redondo maior em área comum). }\end{array}$ & $\begin{array}{l}\text { Extensão, retração e } \\
\text { elevação do úmero. }\end{array}$ \\
\hline Levantador da escápula & $\begin{array}{l}\text { Nivel cervical, cranial ao } \\
\text { redondo maior. }\end{array}$ & $\begin{array}{l}\text { Margem cranial próxima à margem distal da } \\
\text { escápula. }\end{array}$ & $\begin{array}{l}\text { Rotação cranial da } \\
\text { escápula. }\end{array}$ \\
\hline Supracoracoide longo & $\begin{array}{lcr}\text { Projeção } & \text { proximal } & \text { do } \\
\text { coracoide } & \text { (extensiva } & \text { à } \\
\text { superfície } & \text { ventral } & \text { do } \\
\text { coracoide) } & & \end{array}$ & $\begin{array}{l}\text { Distal à superficie articular proximal do úmero, } \\
\text { considerando o posicionamento de inserção do } \\
\text { supracoracoide intermédio e curto. }\end{array}$ & Extensão do ombro. \\
\hline Deltoide escapular proximal & $\begin{array}{lll}\text { Superfície } & \text { proximal } & \text { da } \\
\text { margem } & \text { cranial } & \text { da } \\
\text { escápula. } & & \end{array}$ & Caudal ao vértice da crista deltoide do úmero. & $\begin{array}{lr}\text { Abdução do ŕmero, } \\
\text { estabilização } \\
\text { articulação } & \text { da } \\
\text { ombro. } & \text { do }\end{array}$ \\
\hline Músculo & Origem & Inserção & Ação \\
\hline Redondo maior & $\begin{array}{l}\text { Face caudal distal da } \\
\text { escápula. }\end{array}$ & $\begin{array}{l}\text { Distal à superfície articular proximal do úmero, } \\
\text { cranial ao triceps curto intermédio. }\end{array}$ & $\begin{array}{l}\text { Elevação do úmero, } \\
\text { e flexão da } \\
\text { articulação } \\
\text { glenoumeral. }\end{array}$ \\
\hline Deltoide escapular distal & $\begin{array}{l}\text { Face cranial distal da } \\
\text { escápula. }\end{array}$ & $\begin{array}{l}\text { Caudal ao vértice da crista deltoide do úmero } \\
\text { (sobreposto perpendicularmente á inserção do } \\
\text { deltoide escapular proximal). }\end{array}$ & Extensão do ombro. \\
\hline Escapulo umeral & $\begin{array}{lll}\text { Superficie } & \text { proximal } & \text { da } \\
\text { margem } & \text { caudal } & \text { da } \\
\text { escápula. } & & \end{array}$ & $\begin{array}{l}\text { Caudal à inserção do latíssimo do dorso e } \\
\text { redondo maior. }\end{array}$ & $\begin{array}{l}\text { Elevação, protração } \\
\text { e estabilização do } \\
\text { úmero. }\end{array}$ \\
\hline Coracobraquial dorsal & $\begin{array}{l}\text { Superfície proximal média } \\
\text { da escápula. }\end{array}$ & $\begin{array}{l}\text { Proximal à superficie articular do úmero, cranial } \\
\text { em relação à inserção do coracobraquial ventral e } \\
\text { à crista deltoide, em área restrita. }\end{array}$ & $\begin{array}{l}\text { Estabilização da } \\
\text { cabeça do úmero na } \\
\text { cavidade glenoide, } \\
\text { protração e flexão } \\
\text { do Ombro. }\end{array}$ \\
\hline Supracoracóide intermédio & $\begin{array}{l}\text { Projeção proximal ventral } \\
\text { do coracoide, profundo ao } \\
\text { supracoracoide longo. }\end{array}$ & $\begin{array}{l}\text { Média em relação à superfície articular proximal } \\
\text { do úmero, e entre a inserção do supracoracoide } \\
\text { longo e curto. }\end{array}$ & Extensão do ombro. \\
\hline Supracoracóide Curto & $\begin{array}{l}\text { Sobreposta à junção } \\
\text { escapulocoracoidea, lateral } \\
\text { ao supracoracoideo } \\
\text { intermédio, profundo ao } \\
\text { supracoracoide longo. }\end{array}$ & $\begin{array}{l}\text { Proximal à superficic articular proximal do } \\
\text { úmero. }\end{array}$ & $\begin{array}{l}\text { Extensão e adução } \\
\text { do ombro. }\end{array}$ \\
\hline
\end{tabular}

Ciência Rural, v.43, n.4, abr 2013. 
Tabela 2 - Origem, inserção e ação dos músculos ventrais, superficiais e profundos, e braquiais laterais da cintura peitoral de Caiman latirostris.

\begin{tabular}{|c|c|c|c|}
\hline Músculo & Origem & Inserção & Ação \\
\hline Peitoral & $\begin{array}{l}\text { Ao longo da margem esternal } \\
\text { superficial. }\end{array}$ & $\begin{array}{l}\text { Caudal ao bíceps, na sua porção } \\
\text { proximal. }\end{array}$ & $\begin{array}{l}\text { Adução e retração do } \\
\text { úmero }\end{array}$ \\
\hline Costocoracoide superficial & Margem esternal profunda & $\begin{array}{l}\text { Margem caudal, ao longo da face ventral } \\
\text { do coracoide. }\end{array}$ & $\begin{array}{l}\text { Rotação caudal da cintural } \\
\text { peitoral, retração do } \\
\text { coracoide e/ou da cintura } \\
\text { peitoral. }\end{array}$ \\
\hline Músculo & Origem & Inserção & Ação \\
\hline Costocoracoide profundo & Margem esternal profiunda. & $\begin{array}{l}\text { Margem caudal, especificamente na } \\
\text { projeção proximal ventral do coracoide. }\end{array}$ & $\begin{array}{l}\text { Rotação caudal da } \\
\text { cintura peitoral. }\end{array}$ \\
\hline Coracobraquial ventral & $\begin{array}{l}\text { Proximal à margem esternal, } \\
\text { percorrendo o coracoide. }\end{array}$ & $\begin{array}{l}\text { Superficie média central da epifise } \\
\text { proximal do úmero, em área ampla, cranial } \\
\text { à crista deltoide. }\end{array}$ & $\begin{array}{l}\text { Flexão da articulação do } \\
\text { ombro e retração do } \\
\text { úmero }\end{array}$ \\
\hline Subescapular & $\begin{array}{l}\text { Superficie ventral da escápula } \\
\text { em área ampla. }\end{array}$ & $\begin{array}{l}\text { Protuberância medial à superficie articular } \\
\text { proximal do úmero. }\end{array}$ & $\begin{array}{l}\text { Estabilização da } \\
\text { articulação glenoumeral. }\end{array}$ \\
\hline Músculo & Origem & Inserção & Ação \\
\hline Tríceps longo lateral & $\begin{array}{l}\text { Média, na margem caudal da } \\
\text { escápula. }\end{array}$ & Olecrano & $\begin{array}{l}\text { Flexão do ombro, } \\
\text { extensão do cotovelo. }\end{array}$ \\
\hline Tríceps curto cranial & $\begin{array}{l}\text { Em projeção alongada na } \\
\text { epifise proximal do úmero, até } \\
\text { o limite com o tríceps curto } \\
\text { intermédio, percorrendo área } \\
\text { extensa na diáfise. }\end{array}$ & Olecrano & Extensão do cotovelo. \\
\hline Tríceps curto intermédio & $\begin{array}{l}\text { Proximal à superficie articular } \\
\text { do úmero, percorrendo ao } \\
\text { longo da diáfise do úmero, } \\
\text { cranial ao tríceps curto caudal. }\end{array}$ & Olecrano & Extensão do cotovelo. \\
\hline
\end{tabular}

jacarés, extensivo aos demais crocodilianos, haja vista a não modificação nas alavancas em aspectos gerais (REILLY et al., 2005).

Em observação aos pontos de inserção dos músculos da cintura peitoral, estilopódio e zeugopódio em $\boldsymbol{C}$. latirostris, e seguindo os parâmetros de formação das alavancas, conjetura-se que sejam formadas alavancas interfixas, considerando o ombro como fulcro e o peso do corpo (tronco) como resistência, ou alavancas interpotentes, caso seja considerado, como fulcro, o cotovelo e/ou o punho e, como resistência, a força de reação do solo. A literatura discorre que, nos quadrúpedes, são formadas alavancas de equilíbrio ou relativa neutralidade, relacionando forças em direções distintas em torno de um eixo, consideradas comuns e relacionadas aos músculos extensores (TORTORA \& GRABOWSKI, 2002; HILDEBRAND \& GOSLOW, 2006).

Foi observada uma suposta vantagem mecânica na articulação do ombro de $\boldsymbol{C}$. latirostris em relação ao Alligator mississippiensis, Crocodylus siamensis, C. acutus, Osteolaemus tetraspis e Gavialis gangeticus (MEERS, 2003), para o complexo supracoracoide. Este apresenta inserção lateral no úmero em escala proximal (músculo supracoracoide lateral), média (músculo supracoracoide intermédio) e distal (músculo supracoracoide longo), observada nas espécies acima citadas, todos no ápice da crista 
Tabela 3 - Origem, inserção e ação dos músculos braquiais mediais e laterais do antebraço do Caiman latirostris.

\begin{tabular}{|c|c|c|c|}
\hline Músculo & Origem & Inserção & Ação \\
\hline Tríceps longo medial & $\begin{array}{l}\text { Proximal na margem caudal ventral da } \\
\text { escápula com fixação com tendão duplo, } \\
\text { e proximal na margem ventral caudal do } \\
\text { coracoide. }\end{array}$ & Olecrano & $\begin{array}{l}\text { Flexão do ombro, } \\
\text { extensão do cotovelo. }\end{array}$ \\
\hline Tríceps curto caudal & $\begin{array}{l}\text { Distal à superfície articular proximal do } \\
\text { úmero, ao longo da diáfise medial do } \\
\text { úmero. }\end{array}$ & Olecrano & Extensão do cotovelo. \\
\hline Tríceps longo medial acessório & $\begin{array}{l}\text { Aponeurose proximal do tríceps longo } \\
\text { medial. }\end{array}$ & Olecrano & $\begin{array}{l}\text { Flexão do ombro, } \\
\text { extensão do cotovelo. }\end{array}$ \\
\hline Bíceps & $\begin{array}{l}\text { Projeção proximal da margem dorsal } \\
\text { cranial do coracóide. }\end{array}$ & Tuberosidade radial. & $\begin{array}{l}\text { Extensão do ombro e } \\
\text { flexão do cotovelo. }\end{array}$ \\
\hline Braquial & $\begin{array}{l}\text { Diáfise do úmero, em superfície } \\
\text { alongada, cranial ao biceps e caudal ao } \\
\text { umeroradial. }\end{array}$ & $\begin{array}{l}\text { Distal na tuberosidade } \\
\text { radial. }\end{array}$ & Flexão do cotovelo. \\
\hline Úmeroradial & $\begin{array}{l}\text { Proximal à superfície articular proximal } \\
\text { do úmero, cranial ao braquial. }\end{array}$ & Tuberosidade radial. & flexão do cotovelo. \\
\hline Músculo & Origem & Inserção & Ação \\
\hline Supinador & Epicòndilo cranial do úmero. & $\begin{array}{l}\text { Ao longo da diáfise } \\
\text { cranial do rádio }\end{array}$ & $\begin{array}{l}\text { Supinação e flexão do } \\
\text { antebraço }\end{array}$ \\
\hline Extensor radial longo do carpo & Epicòndilo cranial do úmero. & $\begin{array}{l}\text { Borda dorsal proximal do } \\
\text { osso radial do carpo }\end{array}$ & $\begin{array}{l}\text { Extensão do carpo, flexão } \\
\text { e estabilização da } \\
\text { articulação úmero radial }\end{array}$ \\
\hline Extensor ulnar longo do carpo & Epicòndilo cranial do úmero. & II metacarpo. & Extensão do carpo. \\
\hline Flexor ulnar & Epicòndilo cranial do úmero. & $\begin{array}{l}\text { Diáfise caudal da ulna } \\
\text { (longa). }\end{array}$ & $\begin{array}{l}\text { Flexão do antebraço, e } \\
\text { estabilização postural. }\end{array}$ \\
\hline Abdutor radial & $\begin{array}{l}\text { Epicôndilo cranial do úmero, profiundo ao } \\
\text { supinador. }\end{array}$ & $\begin{array}{l}\text { Terço proximal da diáfise } \\
\text { cranial do rádio. }\end{array}$ & Abdução do antebraço. \\
\hline Extensor radial curto do carpo & $\begin{array}{l}\text { Cabeça radial: terço distal da diáfise do } \\
\text { rádio. Cabeça ulnar: ao longo da diáfise } \\
\text { medial ulnar. }\end{array}$ & $\begin{array}{l}\text { Cabeça radial: sobreposta } \\
\text { à articulação radiocárpica } \\
\text { Cabeça ulnar: sobreposta } \\
\text { à articulação radiocárpica. }\end{array}$ & Extensão do carpo. \\
\hline
\end{tabular}

deltoide, pelo último autor citado. Atribui-se maior força para o músculo supracoracoide longo, em detrimento aos demais componentes do grupo em C. latirostris, devido à maior espessura do diâmetro transverso, diferente das demais espécies, que apresentaram menor número de fibras musculares agrupadas neste músculo. Vale ressaltar que somente existe vantagem real mecânica quando a distância entre o fulcro e o ponto de aplicação de força (braço de ação) é maior do que a distância entre o fulcro e a resistência (braço de resistência) (TORTORA \& GRABOWSKI, 2002; HILDEBRAND \& GOSLOW, 2006).

Ciência Rural, v.43, n.4, abr 2013. 
Tabela 4 - Origem, inserção e ação dos músculos mediais do antebraço do Caiman latirostris.

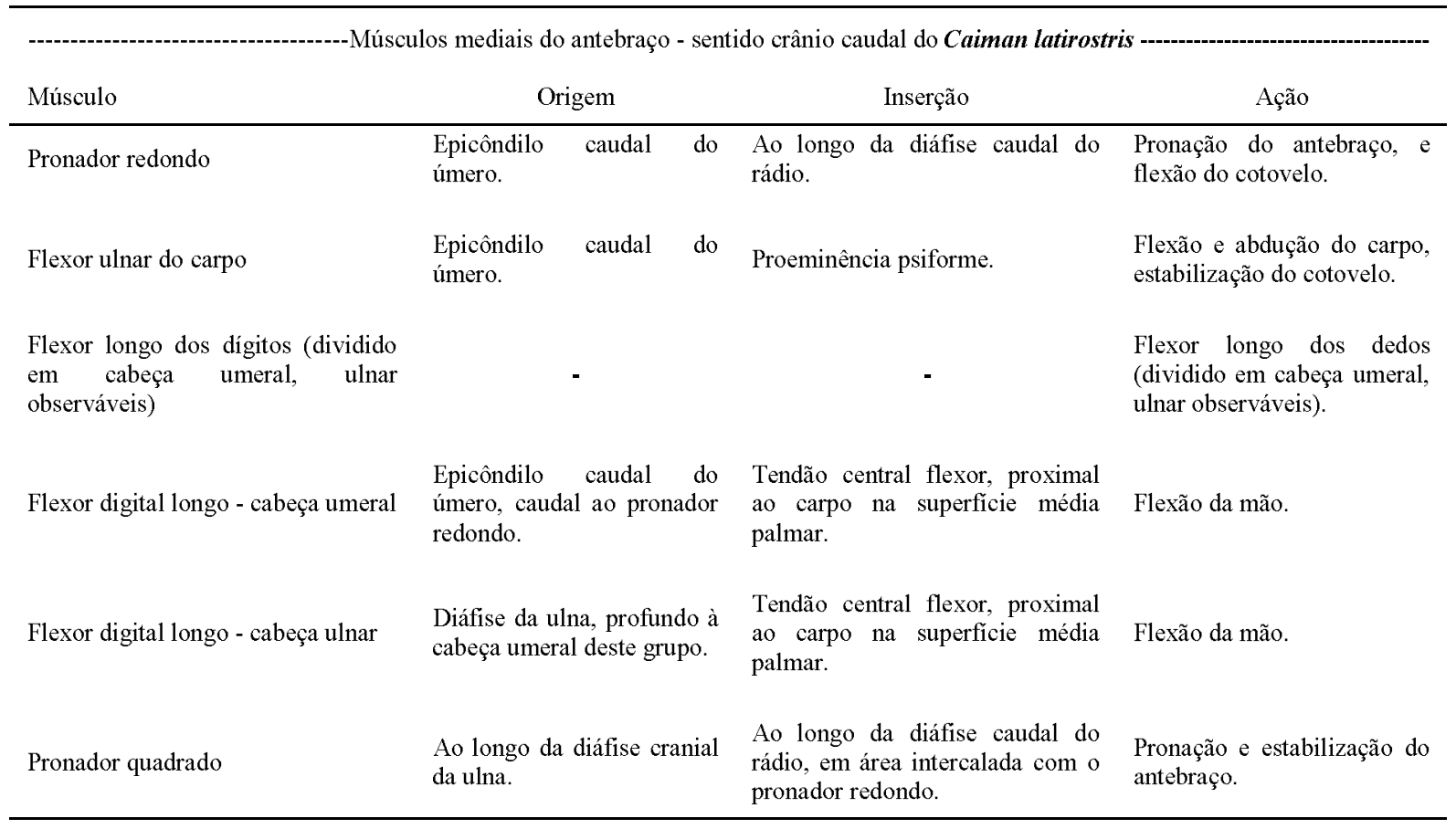

Neste estudo, as inserções do músculo deltoide escapular (proximal e distal) foram observadas caudais ao vértice da crista deltoide, outrora encontrado no ápice da própria crista, estando o tendão do deltoide escapular proximal sobreposto perpendicularmente ao do deltoide escapular distal. O deltoide escapular proximal apresenta fibras extensivas ao músculo úmero radial, próximas ao septo intermuscular úmero radial e o braquial, diferente de duas espécies de $\boldsymbol{A}$. mississippiensis, descritas por MEERS (2003), apresentando a extensibilidade de fibras ao septo intermuscular, entre o úmero radial e o braquial. Vale ressaltar que o músculo deltoide escapular proximal do presente estudo foi indicado como deltoide clavicular pelo último autor citado, não sendo considerado da mesma forma na presente pesquisa, em razão da inexistência de clavícula nos crocodilianos.

Os músculos redondo maior e peitoral foram encontrados em $\boldsymbol{C}$. latirostris, apresentando maior distância longitudinal ao eixo de movimento em relação a A. mississippiensis, C. siamensis, C. acutus, O. tetraspis e G. gangeticus (MEERS, 2003), além de maior suposta vantagem mecânica e mobilidade, levando em consideração a distância da inserção ao eixo de movimento, referenciando a articulação do ombro.

O músculo tríceps foi observado composto por seis cabeças, sendo o músculo tríceps longo medial acessório originado no tendão do tríceps longo medial, como em um exemplar de $\boldsymbol{A}$. mississippiensis e um $\boldsymbol{C}$. acutus, nas pesquisas de MEERS (2003), mediante afirmação de fato pouco comum. Em C. latirostris, foi observado um arco tendíneo unindo o coracoide e a escápula, sendo notado um tendão nitidamente duplo, fundido na fixação da escápula, projetando o tendão do tríceps longo medial, assim como acontece nas últimas espécies citadas antes de $\boldsymbol{C}$. latirostris, mediante afirmação referente a características típicas de espécies predominantemente aquáticas, segundo MEERS (2003). Todas as inserções dos músculos tríceps, neste estudo, foram indicadas no olecrano sem distinção de localização, porque foi observada a formação de um largo tendão comum ao grupo, portanto, a organização segue de acordo com a localização de cada um, em sentido crânio-caudal.

A cabeça carpal do músculo flexor longo dos dedos não foi identificada separadamente nesta pesquisa, como no Alligator mississippiensis, Crocodylus siamensis, Crocodylus acutus, Osteolaemus tetraspi e Gavialis gangeticus, 


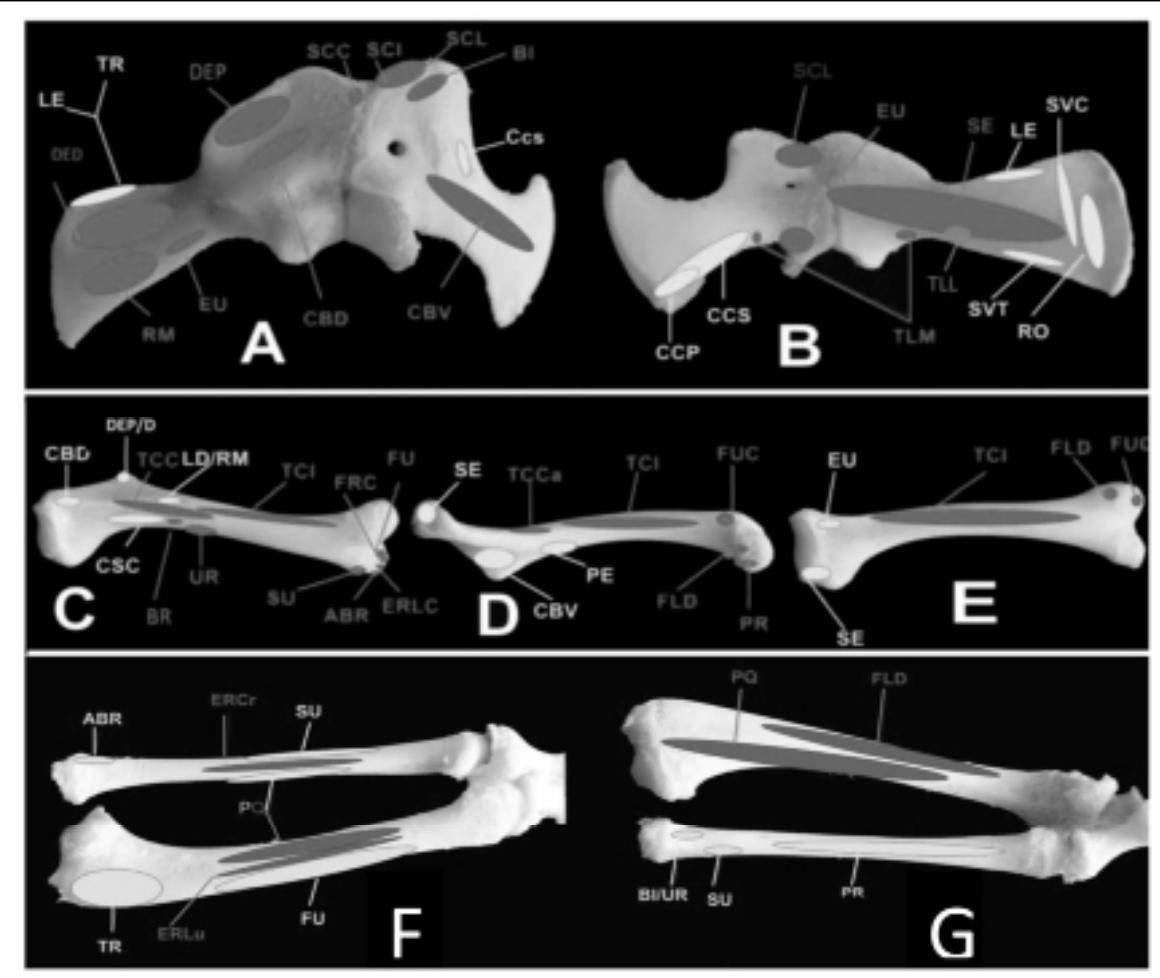

Figura 1 - Fotografia representativa de origem e inserção muscular nas vistas dorsal (A) e ventral (B) da cintura peitoral de Caiman latirostris; cinza $=$ origem; branco $=$ inserção. $\mathrm{DEP}=$ deltoide escapular proximal; $\mathrm{LE}=$ levantador da escápula; $\mathrm{TR}=$ trapézio; $\mathrm{DED}=$ deltoide escapular distal $\mathrm{RM}=$ redondo maior, $\mathrm{EU}=$ escapuloumeral $\mathrm{CBD}=$ corabraquial dorsal $; \mathrm{CBV}=$ coracobraquial ventral; $\mathrm{PE}=$ peitoral; $\mathrm{SCC}=$ supracoracoide curto; $\mathrm{SCI}=$ supracoracoide intermédio; $\mathrm{SCL}=$ supracoracoide longo; $\mathrm{BI}=$ bíceps; $\mathrm{Ccs}=\mathrm{COSTOCORACOIDES} ; \mathrm{CCP}=$ costocoracoide profundo; $\mathrm{CCS}=$ costocoracoide superficial; $\mathrm{EU}=$ escapuloumeral; $\mathrm{TLM}=$ tríceps longo medial; TLL = tríceps longo lateral; $\mathrm{SVT}=$ serrátil ventral torácico; $\mathrm{RO}=$ romboide; SVC $=$ serrátil ventral cervical; $\mathrm{SE}=$ subescapular. Vistas látero-lateral $(C)$, medial $(D)$ e lateral (E), do úmero direito de Caiman latirostris; verde = origem; amarelo $=$ inserção. $\mathrm{CBD}=$ coraco braquial dorsal; $\mathrm{DEP} / \mathrm{D}=$; deltoide escapular proximal e distal; $\mathrm{LD} / \mathrm{RM}=$ latíssimo do dorso e redondo maior; $\mathrm{CSC}=$ complexo supra coracoide; $\mathrm{UR}=$ úmero radial; $\mathrm{TCC}=$ tríceps curto cranial; $\mathrm{TCI}=$ tríceps curto intermédio; $\mathrm{SU}=$ supinador; $\mathrm{ABR}=$ abdutor radial; $\mathrm{ERLC}=$ extensor radial longo do carpo; $\mathrm{ERC}=$ extensor radial curto do carpo; $\mathrm{FU}=$ flexor ulnar. Vistas lateral (F) e medial (G) do estilopódio de Caiman latirostris; cinza = origem; branco $=$ inserção. $\mathrm{ABR}=$ abdurtor radial; $\mathrm{SU}=$ supinador; $\mathrm{PQ}=$ pronador quadrado; $\mathrm{TR}=$ tríceps; $\mathrm{BI}=$ bíceps; $\mathrm{UR}=$ úmero radial; $\mathrm{FLD}=$ flexor longo dos dedos cabeça umeral; $\mathrm{PR}=$ pronador redondo, $\mathrm{ERCr}=$ extensor radial curto do carpo, cabeça radial; $\mathrm{Eu}=$ Extensor ulnar do carpo; $\mathrm{PR}=$ pronador redondo.

observados por Meers (2003), havendo a possibilidade de estar fundida à cabeça ulnar do mesmo grupo.

\section{CONCLUSÃO}

O Caiman latirostris enquadrase nas descrições de crocodilianos que possuem características específicas de espécies predominantemente aquáticas. As diferenças de inserção muscular longitudinais podem sinalizar alteração na amplitude de movimento, extensivas a alterações nos braços de força.

Foi possível reconhecer e predefinir o comportamento da espécie investigada, relacionando duração, direção e dimensão dos níveis de ação. Acredita-se que a ação muscular esteja associada à necessidade da espécie e à filogenia, sendo a primeira em detrimento à segunda. 


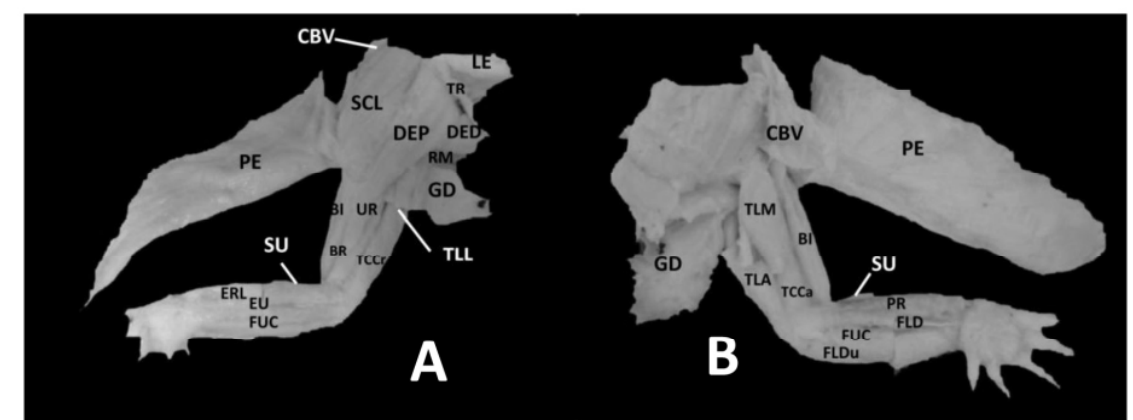

Figura 2 - Fotografia representativa do membro torácico esquerdo de Caiman latirostris na vista lateral (A). $\mathrm{PE}=$ peitoral; $\mathrm{SCL}=$ supracoracoide longo; $\mathrm{DEP}=$ deltoide escapular proximal; DED = deltoide escapular distal; $\mathrm{LE}=$ levantador da escápula; $\mathrm{TR}=$ trapézio; $\mathrm{LD}=$ latíssimo do dorso; $\mathrm{TLL}=$ tríceps longo lateral; $\mathrm{TCCr}=$ tríceps curto cranial; $\mathrm{UR}=$ úmero radial; $\mathrm{BR}=$ braquial; $\mathrm{BI}=$ bíceps; $\mathrm{SU}=$ supinador; $\mathrm{ERL}=$ extensor radial longo do carpo; $\mathrm{EU}=$ extensor ulnar; $\mathrm{FUC}=$ flexor ulnar do carpo. Vista medial (B). $\mathrm{PE}=$ peitoral; TLM = tríceps longo medial; TLA = tríceps longo acessório; $\mathrm{TCCa}=$ tríceps curto caudal; $\mathrm{BI}=$ bíceps; $\mathrm{SU}=$ supinador; $\mathrm{PR}=$ pronador redondo; $\mathrm{FLD}=$ flexor longo dos dedos; FUC = flexor longo da carpo (cabeça umeral); FLDu = flexor longo do carpo cabeça ulnar.

\section{REFERÊNCIAS}

BLOB, R.W.; BIEWENER, A.A. Mechanics of limb bone loading during terrestrial locomotion in the green iguana (Iguana iguana) and American alligator (Alligator mississipiensis). Journal of Experimental Biology, v.204, n.6, p.1099-1122, 2001. Disponível em: <http://jeb.biologists.org/content/204/6/1099.long>. Acesso em: 05 jan. 2012.

BRAZAITIS, P. et al. A summary report of the CITES central South American caiman study. Phase I. Brazil. In: IUCN (Ed.), Crocodiles. Proceedings of Working Meeting of the Crocodile Specialist Group, 9. Gland, Switzerland: The World Conservation Union 1990. 399p. p.100-115.

BRITTON, A. Caiman latirostris (Daudin, 1801). Crocodilian Biology Data Base. 2001. Disponível em: <http://crocodilian. com/cnhc/cbd-gb3.htm>. Acesso em: 05 jan. 2012.

CABELGUEN, J.M. et al. Bimodal locomotion elicited by electrical stimulation of the midbrain in the salamander Notophthalmus viridescens. Journal of Neuroscience, v.23, n.6-p.2434-2436, 2003. Disponível em: <http://www.jneurosci. org/content/23/6/2434.full.pdf+html>. Acesso em: 05 jan. 2012.

DODSON, P. The allure of El Lagart: why do dinosaur paleontologists love alligators, crocodiles, and their kin? Anatomical Record Part A, v.274, p.887-890, 2003. Disponível em: <http://www.sinofossa. org/upfiles/200759112412.pdf>. Acesso em: 10 jan. 2012.

FARMER C.G.; CARRIER D.R. Pelvic aspiration in the American alligator (Alligator mississippiensis). Journal of Experimental Biology, v.203, n.11, p.1679-1687, 2000. Disponível em: <http://jeb. biologists.org/content/203/11/1679.long>. Acesso em: 10 jan. 2012.

FUSCO-COSTA, R.F. et al. Abundância e locais de ocorrência do jacaré-de-papo-amarelo (Caiman latirostris, Alligatoridae) no noroeste da Ilha de Santa Catarina, SC. Biotemas, v.21, n.4, p.183-187, 2008. Disponível em: <http://jeb.biologists.org/ content/203/11/1679.long>. Acesso em: 20 jan. 2012.
HILDEBRAnD, M.; GOSLOW, G. Análise da estrutura dos vertebrados. 2.ed. São Paulo: Atheneu, 2006. 700p.

LAITMAN, J.T. It's not all in the hips: crocodylian forelimb anatomy and evolution. Anatomical Record Part B, v.275, p.182, 2003. Disponível em: <http://onlinelibrary.wiley.com/ doi/10.1002/ar.b.10039/pdf >. Acesso em: 20 jan. 2012.

MEERS, M.B. Crocodylian forelimb musculature and its relevance to archosauria. Anatomical Record Part A, v.274, p.891-916, 2003. Disponível em: <http://onlinelibrary.wiley.com/ doi/10.1002/ar.a.10097/pdf>. Acesso em: 20 jan. 2012.

QUEIROZ P.P.R.; AOYAMA P.M.M. List of studies on the Alligator-de-snouted Caiman (Caiman latirostris Daudin, 1802) 2009. Disponível em: <http://crocodilian.com/cnhc/csp_ clat.htm>. Acesso em: 20 jan. 2012.

REILLY, S.M. Locomotion in the quail (Coturnix japaonica) the kinematics of walking and increasing speed. Journal of Morphology, v.243, p.173-185, 2000. Disponível em: <http:// www.ohio.edu/people/reilly/pdfjmorph\%202000\%20\%20243\%20 \%20173-185.pdf>. Acesso em: 20 jan. 2012.

REILLY, S.M.; BLOB, R.W. Motor control of locomotor hindlimb posture in the American alligator (Alligator mississippiensis). Journal of Experimental Biology, v.206, n.23, p.4327-4340, 2003. Disponível em: <http://jeb.biologists.org/content/206/23/4327. full.pdf+html>. Acesso em: 20 jan. 2012.

REILLY, S.M. et al. Hindlimb function in the alligator: integrating movements, motor patterns, ground reaction forces and bone strain of terrestrial locomotion. Journal of Experimental Biology, v.208, n.6, p.993-1009, 2005. Disponível em: <http:// jeb.biologists.org/content/208/6/993.full.pdf + html>. Acesso em: 20 jan. 2012.

TORTORA, G.J.; GRABOWSKI, S.R. Princípios de anatomia humana e fisiologia. 9.ed. Rio de Janeiro: Guanabara Koogan, 2002. 1088p. 